\title{
Resistance of Postharvest Biocontrol Yeasts to Oxidative Stress: A Possible New Mechanism of Action
}

\author{
Raffaello Castoria, Leonardo Caputo, Filippo De Curtis, and Vincenzo De Cicco
}

First, third, and fourth authors: Dipartimento di Scienze Animali, Vegetali e dell'Ambiente, Università del Molise, Via F. De Sanctis, 86100, Campobasso, Italy; and second author: Istituto di Scienze delle Produzioni Alimentari, C.N.R. Viale Einaudi 51, 70125 Bari, Italy. Accepted for publication 29 November 2002.

\begin{abstract}
Castoria, R., Caputo, L., De Curtis, F., and De Cicco, V. 2003. Resistance of postharvest biocontrol yeasts to oxidative stress: A possible new mechanism of action. Phytopathology 93:564-572.

We detected the generation of the reactive oxygen species (ROS) superoxide anion $\left(\mathrm{O}_{2}^{\bar{*}}\right)$ and hydrogen peroxide $\left(\mathrm{H}_{2} \mathrm{O}_{2}\right)$ in apple wounds immediately after wounding, and assessed the relationships between (i) timely colonization of apple wounds by biocontrol yeasts, (ii) resistance of these microorganisms to oxidative stress caused by ROS, and (iii) their antagonism against postharvest wound pathogens. We analyzed a model system consisting of two yeasts with higher (Cryptococcus laurentii LS-

LS-28 exhibited faster and greater colonization of wounds than LS-11. In contrast to LS-28, the number of LS-11 cells dropped 1 and $2 \mathrm{~h}$ after application, and then increased only later. In vitro, LS-28 was more resistant to ROS-generated oxidative stress. The combined application of biocontrol yeasts and ROS-deactivating enzymes in apple wounds prevented the decrease in number of LS-11 cells mentioned above, and enhanced colonization and antagonistic activity of both biocontrol yeasts against $B$. cinerea and $P$. expansum. Polar lipids of LS-11 contained the more unsaturated and oxidizable $\alpha$-linolenic acid, which was absent in LS-28. Resistance to oxidative stress could be a key mechanism of biocontrol yeasts antagonism against postharvest wound pathogens.
\end{abstract} 28) or lower (Rhodotorula glutinis LS-11) antagonistic activity against the postharvest pathogens Botrytis cinerea and Penicillium expansum.

The control of postharvest diseases of fruits and vegetables is still based primarily on the use of synthetic fungicides, although the demand for produce that is free of chemical residues and the emergence of fungicide-resistant pathogen strains are constantly increasing. Different strategies have been proposed as alternatives to fungicides. Utilization of antagonist yeasts appears to be a promising technology (27). Some antagonist-based products are commercially available and others are currently at varying stages of development. Understanding the mode or modes of action of antagonists is important for identifying useful traits that could be upgraded by genetic tools, for improving their performances and reliability through the development of formulations enhancing the expression of such traits, and for establishing screening criteria in the selection of new potential biocontrol agents. Mechanisms which have been reported to play a role in the biocontrol activity of antagonistic yeasts include competition for space and nutrients, activation of host defenses, and production of extracellular depolymerases which putatively act on pathogen cell walls $(5,6,9,10$, 15,25-28). Competition for space and nutrients has been demonstrated as a major mechanism in the antagonism of biocontrol yeasts against postharvest fungal pathogens $(5,6,9,10,26)$.

Postharvest fungal pathogens invade tissues of horticultural and fruit crops mainly through wounds. Therefore, wound competence is pivotal for biocontrol yeasts to successfully compete for space and nutrients against these fungi (9). No reports exist in the literature focusing on the traits providing these biocontrol agents with a sound wound competence; in other words, the subset of mechanisms underlying a complex aspect of pathogen-antagonist interaction, such as competition for space and nutrients, are still elusive. The number of live antagonist cells present in wound sites

Corresponding author: R. Castoria; E-mail address: castoria@unimol.it

Publication no. P-2003-0224-01R

(C) 2003 The American Phytopathological Society
Additional keyword: Malus domestica.

can be a limiting factor for effective protection against infection by pathogens (9). Therefore, a timely colonization of wounds by biocontrol agents is crucial for their successful competition against pathogens.

Wounding of plant tissue is associated with increased lypolitic acyl hydrolase activity, phospholipase and lipoxygenase activation, formation of free radicals (e.g., semiquinones and lipoperoxyl radicals) and, possibly, reactive oxygen species (ROS) such as hydrogen peroxide $\left(\mathrm{H}_{2} \mathrm{O}_{2}\right)$ and the superoxide anion $\left(\mathrm{O}_{2}^{\overline{\mathbf{}}}\right)(8,12$, $16,23,24)$. The latter result from the oxidative burst in plant tissues challenged by incompatible pathogens or treated with elicitors (3). In living organisms, ROS and free radicals induce oxidative stress that can have many detrimental effects, including oxidation of unsaturated fatty acids of membrane polar lipids (PL) $(7,13,24)$. Any microorganism that attempts to colonize fresh wounds presumably has to cope with the oxidative stress caused as a consequence of wounding.

Recently, it was reported that the necrotrophic pathogen Botrytis cinerea produces or induces ROS generation in plants during the early stages of infection, possibly to kill host cells $(11,20,22)$. These considerations led us to test the hypothesis that an effective antagonist should possess resistance to oxidative stress to ensure rapid colonization of wounds. For this purpose, we assessed $\mathrm{O}_{2}^{\overline{-}}$ and $\mathrm{H}_{2} \mathrm{O}_{2}$ generation immediately after wounding of apple fruit, and analyzed a model system consisting of two yeast isolates which previously had been shown to have higher (Cryptococcus laurentii LS-28) and lower (Rhodotorula glutinis LS-11) antagonistic activity $(4,18)$. These biocontrol agents were compared with respect to (i) colonization rates of freshly generated apple wounds; (ii) in vitro resistance to $\mathrm{O}_{2}^{\overline{-}}$ and $\mathrm{H}_{2} \mathrm{O}_{2}$-generated oxidative stress; (iii) influence of the ROS-deactivating enzymes (RDE) superoxide dismutase and catalase on their colonization of apple wounds and their antagonistic activity against $B$. cinerea and Penicillium expansum; and (iv) the fatty acid pattern of their polar (membrane) lipids. 


\section{MATERIALS AND METHODS}

Apples (cv. Annurca) harvested at the same time from the same orchard and kept in cold storage at $5^{\circ} \mathrm{C}$ for 1 or 7 months after harvest were used in all experiments. Prior to each experiment, apples were kept at room temperature for $24 \mathrm{~h}$, surface disinfected with $1 \%$ commercial sodium hypochlorite for $2 \mathrm{~min}$, and then rinsed with sterile water. Hydrogen peroxide was titrated prior to its utilization in each experiment according to Black and Brandt (2).

Determination of $\mathrm{O}_{2}^{\overline{-}}$ and $\mathrm{H}_{2} \mathrm{O}_{2}$ in wounded apple tissue. Time-course determination of $\mathrm{O}_{2}^{\overline{-}}$ and $\mathrm{H}_{2} \mathrm{O}_{2}$ accumulation was performed immediately after wounding. Wounded apple tissue consisted of fruit explants ( $5 \mathrm{~mm}$ in diameter by $2 \mathrm{~mm}$ high) having an exposed surface of approximately $50 \mathrm{~mm}^{2}$, equivalent to that of wounds produced for antagonistic activity assays (described below). Explants were withdrawn with a cork borer from near the stem and immediately used for ROS determinations. In each experiment there were nine explants, each deriving from a different fruit, at each analyzed time interval. Experiments were performed three times.

Assessment of $\mathrm{O}_{2}^{-}$was performed according to the method by Sutherland and Learmonth (21) with slight modifications (1), by determining the specific reduction of XTT (2,3-bis(2-metoxy-4nitro-5-sulphophenyl)-5-[(phenylamino) carbonyl]-2H-tetrazolium hydroxide, sodium salt) to formazan by $\mathrm{O}_{2}^{\bar{a}}$. After withdrawal, the explants were immediately put in multiwell plates (volume of microwells, $350 \mu \mathrm{l}$ ) containing $200 \mu \mathrm{l}$ of $0.5 \mathrm{mM} \mathrm{XTT} \mathrm{(X4251}$ Sigma; Sigma-Aldrich Chemical Co., St. Louis) in $50 \mathrm{mM}$ K phosphate buffer, pH 7.8 ("wound" treatment). In order to confirm the role of $\mathrm{O}_{2}^{\overline{-}}$ in this reduction, other explants were put in the same solution in the presence of Superoxide dismutase (SOD) (EC 1.15.1.1, Fluka 86200; Sigma-Aldrich Chemical Co.) at $37.5 \mathrm{U} / \mathrm{ml}$ ("wound + SOD" treatment). The same treatments also were performed with heat-inactivated SOD. Multiwell plates were incubated for $0,15,30,60,120,180$, and $240 \mathrm{~min}$ in gentle shaking $(60 \mathrm{rpm})$. Finally, the explants were removed and absorbance at $490 \mathrm{~nm}$ was measured in a microplate reader (Microplate reader 550; Biorad Laboratories, Hercules, CA). XTT reduction to formazan was expressed as mean absorbance values per wound \pm SD.

Determination of $\mathrm{H}_{2} \mathrm{O}_{2}$ was performed by the xylenol orange method $(14,29)$ with slight modifications. After withdrawal, the explants were immediately placed in $25 \mathrm{mM}$ Na phosphate buffer pH 7.2 ("wound" treatment) or, alternatively, in the same solution containing catalase (CAT, EC 1.11.1.6, C9322; Sigma-Aldrich Chemical Co.) at $225 \mathrm{U} / \mathrm{ml}$ ("wound + CAT" treatment), or superoxide dismutase at $37.5 \mathrm{U} / \mathrm{ml}$ ("wound + SOD" treatment). The same treatments also were performed with heat-inactivated CAT or SOD. Explants were incubated in open vials and shaken at $60 \mathrm{rpm}$ for $0,15,30,60,120,180$, and $240 \mathrm{~min}$. At the end of the various time intervals, explants were discarded and an equal volume of $2 \mu \mathrm{M}$ xylenol orange (Sigma X0127; Sigma-Aldrich Chemical Co.) in $50 \mathrm{mM} \mathrm{H}_{2} \mathrm{SO}_{4}, 200 \mathrm{mM}$ sorbitol, and $0.5 \mathrm{mM}$ ammonium ferrous sulfate was added in each vial. After $30 \mathrm{~min}$, absorbance was measured at $650 \mathrm{~nm}$. A standard curve of $\mathrm{H}_{2} \mathrm{O}_{2}$ (Carlo Erba 412072; Carlo Erba Co., Milano, Italy) was prepared and used as a reference for the quantification of this reactive oxygen species. Hydrogen peroxide was expressed as mean values of nmoles per wound $\pm \mathrm{SD}$.

Resistance of biocontrol agents to ROS-generated oxidative stress. In vitro assays of resistance of the biocontrol yeasts LS-11 and LS-28 to $\mathrm{O}_{2}^{\overline{\mathbf{s}}}$-generated oxidative stress were performed using the superoxide generating system represented by xanthine and xanthine oxidase (EC 1.1.3.22) $(7,13)$ as follows: yeasts were grown in $50 \mathrm{ml}$ of Lilly-Barnett (LB medium) (17) in shake cultures at $23^{\circ} \mathrm{C}$ until they reached the logarithmic phase (16 to $18 \mathrm{~h}$ ). Cells were collected by centrifugation, washed twice with sterile distilled water, and resuspended in $20 \mathrm{mM}$ Tris- $\mathrm{HCl}, \mathrm{pH} \mathrm{7.5,} \mathrm{and}$ sucrose $0.5 \%$ (wt/vol) (THS) at approximately $1 \times 10^{7} \mathrm{CFU} / \mathrm{ml}$. Aliquots $(1 \mathrm{ml})$ of both yeast suspensions were added to flasks containing $25 \mathrm{ml}$ of freshly prepared THS with the $\mathrm{O}_{2}^{\overline{-}}$-generating system (100 $\mu \mathrm{M}$ xanthine, Sigma X4002, xanthine oxidase, Sigma X4376, at $0.052 \mathrm{U} / \mathrm{ml}$; Sigma-Aldrich Chemical Co.), or, alternatively, to THS alone, THS with xanthine, or THS with xanthine oxidase (controls). Flasks were incubated for $1 \mathrm{~h}$ in the same conditions as during yeast growth. All treatments were performed in triplicate. Following incubation, cells were collected by centrifugation, washed with fresh LB, suspended in $25 \mathrm{ml}$ of the same medium, and grown as above. Determination of viable cell numbers was carried out by sampling the cultures $1 \mathrm{~h}$ before and 0,1 , $3,5,9$, and $24 \mathrm{~h}$ after the different treatments, and by plating the samples on nutrient yeast dextrose agar for the count of CFU appearing after 4 days. Viability of cells was expressed as mean values of $\log \mathrm{CFU} / \mathrm{ml} \pm \mathrm{SD}$. Experiments were performed three times.

In vitro assays of resistance to $\mathrm{H}_{2} \mathrm{O}_{2}$-generated oxidative stress by the biocontrol yeasts LS-11 and LS-28 were carried out as described by Chaput and Sels (7). A cell suspension of both yeasts (approximately $5 \times 10^{6} \mathrm{CFU} / \mathrm{ml}$ ) from cultures in logarithmic phase was prepared in sterile distilled water. Aliquots $(1 \mathrm{ml})$ of yeast suspensions were added to $25 \mathrm{ml}$ of fresh LB alone or containing, alternatively, 2 or $20 \mathrm{mM} \mathrm{H}_{2} \mathrm{O}_{2}$, and incubated for $1 \mathrm{~h}$ in the same conditions as during growth (see above). All treatments were performed in triplicate. Following incubation, yeast cells were washed and transferred to fresh LB. Cultures were sampled at the same time intervals as in the assays of resistance to $\mathrm{O}_{2}^{\overline{\boldsymbol{\alpha}}-}$ generated oxidative stress described above. Viability of cells was expressed as mean values of $\log \mathrm{CFU} / \mathrm{ml} \pm \mathrm{SD}$. Experiments were performed three times.

Apple wound colonization by biocontrol agents. Isolates LS11 and LS-28 were grown in $50 \mathrm{ml}$ of nutrient yeast dextrose broth (NYDB) for 24 to $36 \mathrm{~h}$ in shake cultures at $23^{\circ} \mathrm{C}$. Cells were collected by centrifugation, washed twice, and suspended $(1 \times$ $10^{6} \mathrm{CFU} / \mathrm{ml}$ ), alternatively, in sterile distilled water, SOD solution

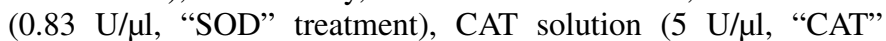
treatment), SOD plus CAT solution ( 0.83 and $5 \mathrm{U} / \mu \mathrm{l}$, respectively, "RDE" treatment), or bovine serum albumin (BSA, Sigma A7511; Sigma-Aldrich Co.) solution $(1.5 \mu \mathrm{g} / \mu \mathrm{l}$, corresponding to the protein concentration of SOD + CAT solution, "BSA" treatment). Apple wounds with an exposed surface equivalent to that of the explants of ROS determination experiments (described previously) were produced as described previously. Immediately after wounding, they were treated with $30 \mu \mathrm{l}$ of each of the different yeast cell suspensions. In each treatment, every time interval analyzed for wound colonization by yeast cells consisted of three replicates, each represented by nine wounds (three wounds per apple). Apples were kept in the dark at $20^{\circ} \mathrm{C}$ and $90 \%$ relative humidity (RH). Time-course analyses of colonization were performed at $0,1,2$, and $4 \mathrm{~h}$ by counting the number of $\mathrm{CFU}$ as described previously (18). Wound colonization was expressed as mean values of $\log \mathrm{CFU}$ per wound $\pm \mathrm{SD}$. Experiments were performed two times.

Antagonistic activity assays. Biocontrol yeasts LS-11 and LS28 were grown as described previously. Yeast suspensions $(1 \times$ $10^{8} \mathrm{CFU} / \mathrm{ml}$ ) were prepared, alternatively, in sterile distilled water, SOD plus CAT solution $(0.83$ and $5 \mathrm{U} / \mu \mathrm{l}$, respectively, "RDE" treatment), or BSA solution $(1.5 \mu \mathrm{g} / \mu \mathrm{l}$, corresponding to the protein concentration of SOD + CAT solution, "BSA" treatment). BSA was added as a control for assessing the effect of exogenous protein (nutrient) addition on antagonistic activity. The assays were performed in apple wounds (five wounds/apple) produced as described previously. Explants were discarded, and $30 \mu \mathrm{l}$ of the different yeast cell suspensions were added to wounds immediately after wounding. After 1 to $1.5 \mathrm{~h}$, wounds were inoculated with $15 \mu \mathrm{l}$ of freshly prepared conidial suspension of $B$. cinerea Pers. $\left(2 \times 10^{4}\right.$ spores per $\left.\mathrm{ml}\right)$ or $P$. expansum Link. $(1 \times$ 
$10^{4}$ spores per $\mathrm{ml}$ ). Each treatment consisted of three replicates with three apples per replicate. Apples were kept at $20^{\circ} \mathrm{C}$ in the dark at $90 \% \mathrm{RH}$ for up to 5 to 7 days, when the number of infected wounds was determined. Experiments were performed three times. Experiments with the same fungal pathogen and with apples of the same age were considered as a sole experimental block. Results were expressed as percentages of infected wounds and converted to Bliss angular values (arcsine $\sqrt{ } \%$ ) before statistical analyses. Variances were homogenous and results were similar among repetitions of the experiments within the same experimental block; therefore, transformed data from each block were submitted to factorial analysis of variance by using the PROC general linear models (GLM) of SPSS (release 8.0.0 for Windows; SPSS Inc., Chicago, IL). Finally, data from the same experimental block were combined for presentation of the results in order to show the influence of the antagonists (LS-11, LS-28, or no antagonist) and the amendments (BSA, $\mathrm{H}_{2} \mathrm{O}$, or RDE) on the percentage of infected wounds. Means from the same experi- mental block were separated with the least significant difference (LSD) test $(P<0.01)$.

Extraction, purification and analysis of PL. Isolates LS-11 and LS-28 were cultured as described previously and lipids were extracted with chloroform/methanol (2:1, vol/vol) containing butylated hydroxy toluene (SIGMA B1378; Sigma-Aldrich Chemical Co.). PL were purified by thin-layer chromatography as described elsewhere (19) and transmethylated by using sodium methoxide (Fluka 71750; Sigma-Aldrich Chemical Co.). All solvents (high-performance liquid chromatography grade) used were from Merck AG (Darmstadt, Germany) and reference standards of fatty acids were from Sigma (Sigma-Aldrich Chemical Co.). Methyl esters were analyzed by gas chromatography-mass spectrometry (SCAN method) utilizing a gas chromatograph HP 5890 series II, plus an HP 5989 B mass spectrometer (Hewlett-Packard, Palo Alto, CA). Instrument control and data reduction were accomplished with the HP G 1034C software for the MS Chem Station (DOS series, Hewlett-Packard). Peak area values given

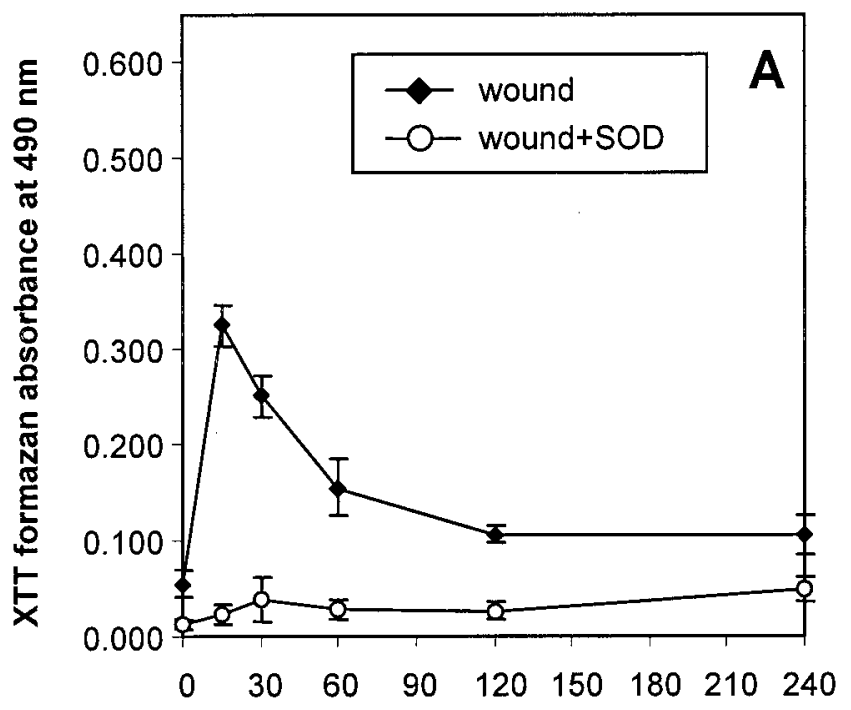

Minutes after wounding

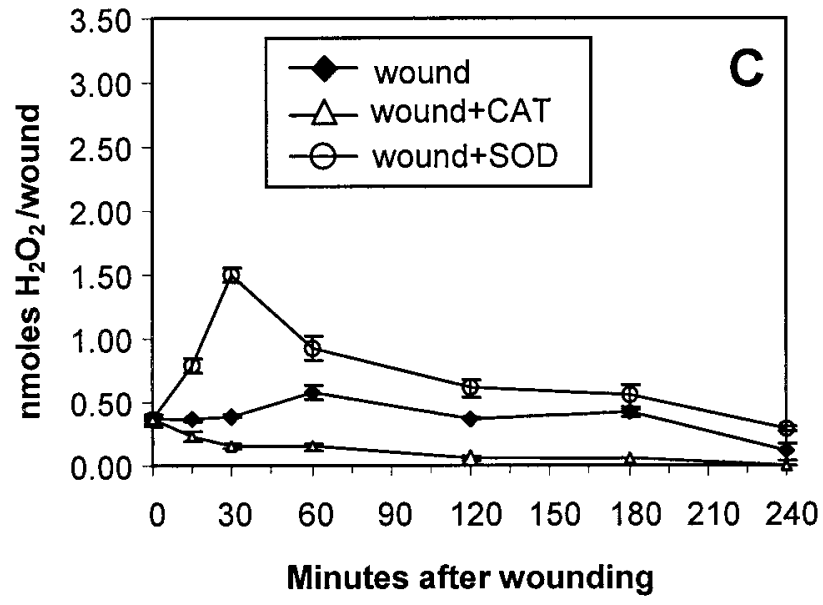

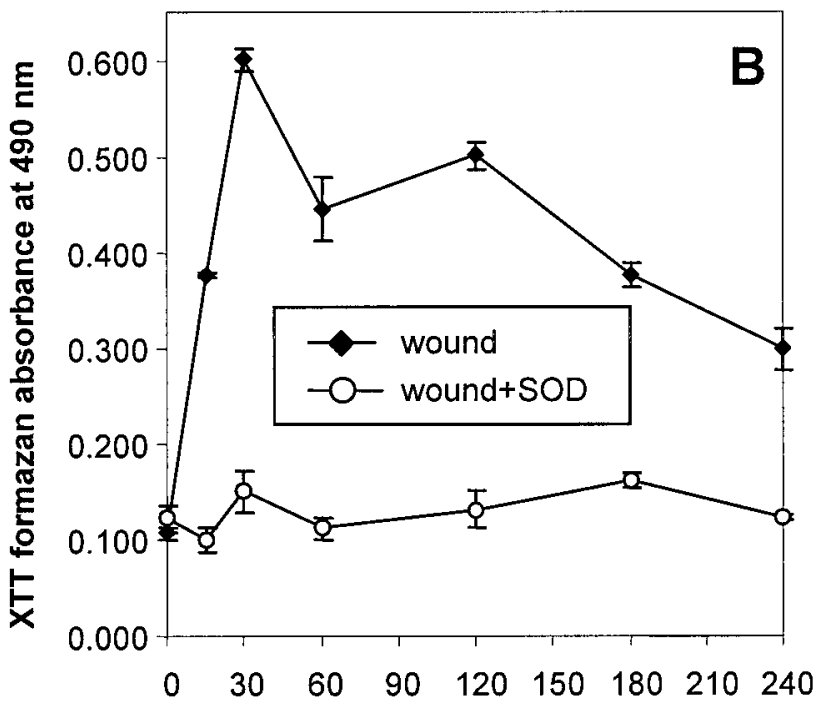

Minutes after wounding

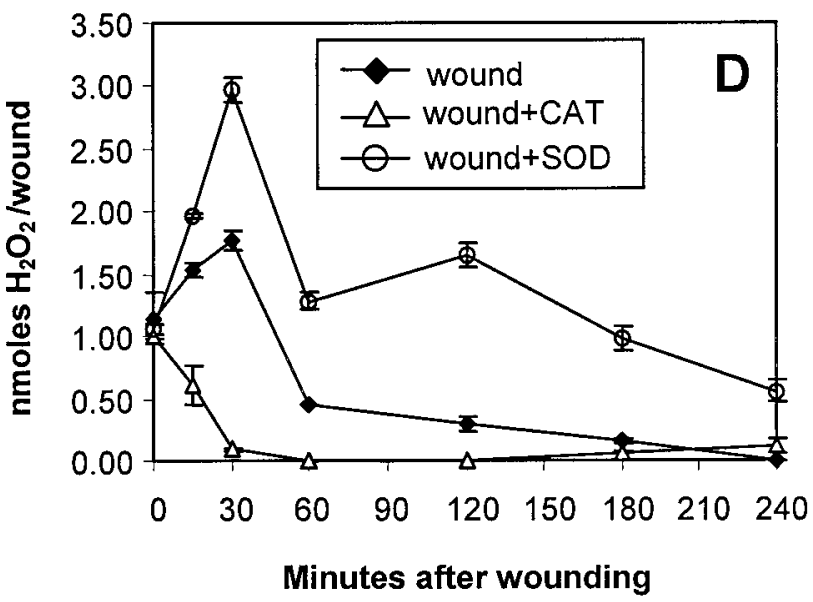

Fig. 1. Time-course accumulation of $\mathbf{A}$ and $\mathbf{B}, \mathrm{O}_{2}^{\overline{\boldsymbol{\beta}}}$ and $\mathbf{C}$ and $\mathbf{D}, \mathrm{H}_{2} \mathrm{O}_{2}$ in wounds of $\mathbf{A}$ and $\mathbf{C}, 1$-month-old and $\mathbf{B}$ and $\mathbf{D}, 7$-month-old stored apples. $\mathrm{O}_{2}^{\overline{\bar{\beta}}}$ was measured determining the absorbance at $490 \mathrm{~nm}$ caused by specific reduction of XTT (2,3-bis(2-metoxy-4-nitro-5-sulphophenyl)-5-[(phenylamino) carbonyl]$2 \mathrm{H}$-tetrazolium hydroxide, sodium salt) to respective formazan. Data were expressed as absorbance values per wound. $\mathrm{H}_{2} \mathrm{O}_{2}$ was measured by the xylenol orange method and data were expressed as nmoles of $\mathrm{H}_{2} \mathrm{O}_{2}$ per wound. Superoxide dismutase (SOD) and catalase (CAT) were added as controls in $\mathrm{O}_{2}^{\overline{-}}$ and $\mathrm{H}_{2} \mathrm{O}_{2}$ determinations, respectively, in order to establish the reliability of methods. SOD was added in $\mathrm{H}_{2} \mathrm{O}_{2}$ determinations to assess the known role of $\mathrm{O}_{2}^{\frac{2}{2}}$ as a possible source for the generation of hydrogen peroxide. Values are the pooled means \pm SD (bars) of three experiments. 
were the results of the integration of the SCAN chromatograms. Identification was made on the basis of reference standards. Purification and analyses of polar lipids were repeated twice.

\section{RESULTS}

Determination of $\mathrm{O}_{2}^{\overline{-}}$ and $\mathrm{H}_{2} \mathrm{O}_{2}$ in wounded apple tissue. A sustained generation of $\mathrm{O}_{2}^{\overline{-}}$ (Fig. $1 \mathrm{~A}$ and $\mathrm{B}$ ) and $\mathrm{H}_{2} \mathrm{O}_{2}$ (Fig. $1 \mathrm{C}$ and $\mathrm{D}$ ) occurred in apple fruit tissue immediately after wounding. In 1-month-old stored apples, $\mathrm{O}_{2}^{\overline{-}}$ and $\mathrm{H}_{2} \mathrm{O}_{2}$ reached their peaks of accumulation 15 and 60 min after wounding, respectively (Fig. 1A and C). Superoxide anion was markedly higher at peak than time 0 , and then gradually decreased until $120 \mathrm{~min}$, after which it remained stable (Fig. 1A). Hydrogen peroxide remained stable at elevated levels for up to $180 \mathrm{~min}$, then decreased at $240 \mathrm{~min}$ (Fig. 1C). In older, stored apples, levels of $\mathrm{O}_{2}^{\overline{-}}$ and $\mathrm{H}_{2} \mathrm{O}_{2}$ were about twice those of younger tissue (Fig. 1B and D). Interestingly, addition of SOD resulted in a faster (peak at $30 \mathrm{~min}$ ) and higher generation of $\mathrm{H}_{2} \mathrm{O}_{2}$ in young apples (Fig. 1C). An analogous effect was recorded in old apples, in which the addition of SOD caused an increase of $\mathrm{H}_{2} \mathrm{O}_{2}$ at all time intervals (Fig. 1D). As expected, SOD (Fig. 1A and $\mathrm{B}$ ) lowered the levels of $\mathrm{O}_{2}^{\overline{-}}$ considerably in both young and old apples, as did CAT for levels of $\mathrm{H}_{2} \mathrm{O}_{2}$ (Fig. 1C and D).

Resistance of biocontrol agents to ROS-generated oxidative stress. In in vitro experiments, the more active antagonist LS-28 showed higher resistance to both $\mathrm{O}_{2}^{\overline{-}}$ and $\mathrm{H}_{2} \mathrm{O}_{2}$-generated oxidative stress than the less active LS-11 (Figs. 2 and 3). Following $1 \mathrm{~h}$ of treatment with the $\mathrm{O}_{2}^{\overline{\mathbf{s}}}$-generating system (XAN $\left.+\mathrm{XO}\right)$, populations of LS-11 were considerably lower than the respective controls (no treatment $\left[\mathrm{H}_{2} \mathrm{O}\right]$ or treatments with XAN or XO) at all time intervals (Fig. 2A), and continuously declined until $9 \mathrm{~h}$ after treatment. In the case of isolate LS-28, no decreases were recorded over the time course of the experiments compared with the control treatments. In fact, significant increases in the number of CFU were recorded until $9 \mathrm{~h}$ in all treatments, even with the $\mathrm{O}_{2}^{\overline{\bar{j}}}$-generating system (Fig. 2B).

The two biocontrol agents also exhibited an analogous behavior following in vitro incubation with $\mathrm{H}_{2} \mathrm{O}_{2}$ (Fig. 3A and B). After $1 \mathrm{~h}$ of treatment with 2 and $20 \mathrm{mM} \mathrm{H}_{2} \mathrm{O}_{2}$, CFU of both isolates were lower than the respective controls $\left(\mathrm{H}_{2} \mathrm{O}\right)$ at all time intervals and a dose-dependent effect was clearly observed, although much less pronounced for LS-28. Lower levels of LS-28 CFU were recorded with both 2 and $20 \mathrm{mM} \mathrm{H}_{2} \mathrm{O}_{2}$ at $0,1,3$, and $5 \mathrm{~h}$ after treatment, compared with the control (Fig. 3B); however, unlike LS-11 (Fig. 3A), they did not substantially differ from the CFU used at the beginning of treatments (time $-1 \mathrm{~h}$ ). Further, in the case of $2 \mathrm{mM}$ $\mathrm{H}_{2} \mathrm{O}_{2}$, CFU of LS-28 started to increase at $5 \mathrm{~h}$ compared with time $-1 \mathrm{~h}$.

Apple wound colonization by biocontrol agents. The more active antagonist LS-28 colonized fresh apple wounds more rapidly and to a greater CFU level than did LS-11 on both young and old apples (Fig. 4A to D). The number of LS-28 CFU steadily increased from 1 to $4 \mathrm{~h}$ (Fig. 4B and D). By contrast, CFU of LS11 dropped dramatically $1 \mathrm{~h}$ after application, and started to increase at $2 \mathrm{~h}$ in young apples and at $4 \mathrm{~h}$ in old ones (Fig. 4A and C). CFU of both antagonists increased up to $24 \mathrm{~h}$ after application, but LS-28 colonization of wounds still was greater than that of LS-11 (data not shown). Treatment with SOD + CAT (RDE) had the most positive effects on the colonization of apple wounds by

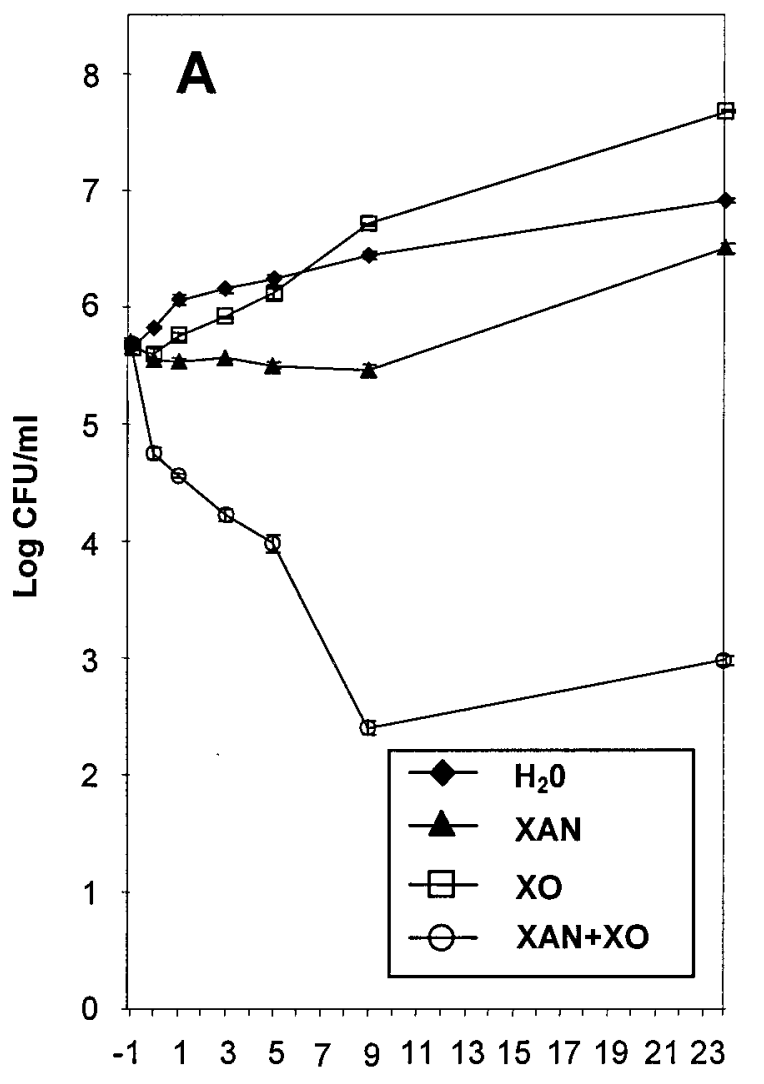

Time (hours)

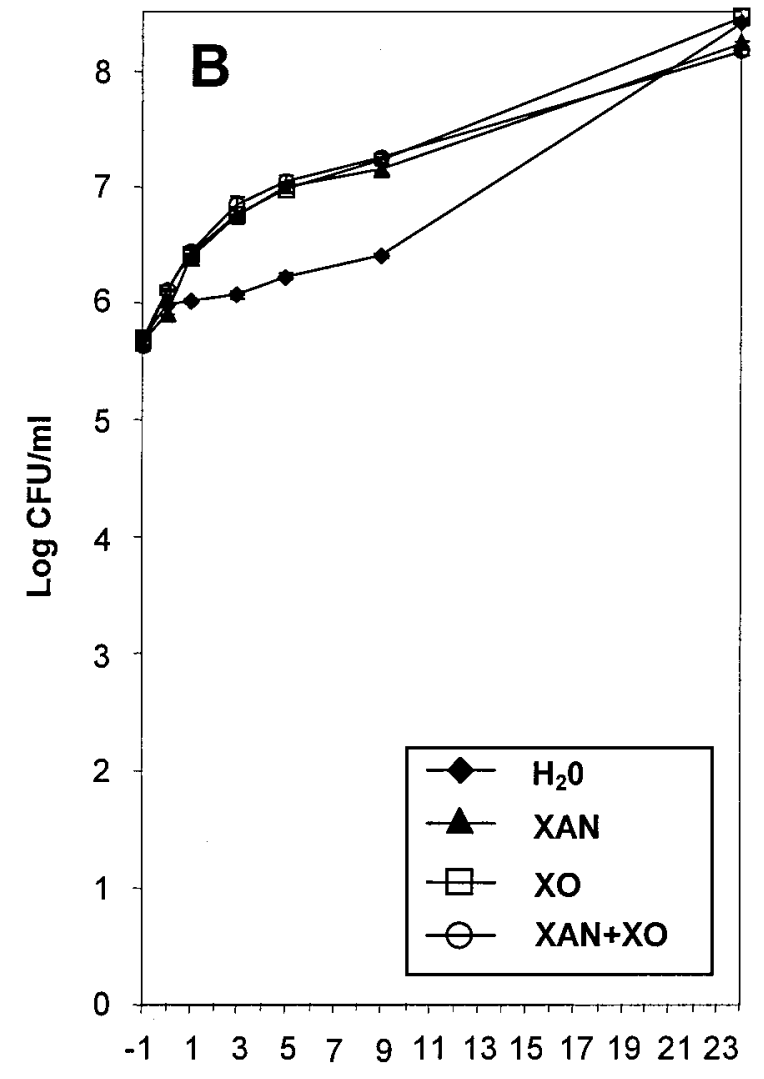

Time (hours)

Fig. 2. In vitro survival of the biocontrol yeasts A, Rhodotorula glutinis LS-11 and B, Cryptococcus laurentii LS-28, expressed as log CFU, following $1 \mathrm{~h}$ of treatment with an $\mathrm{O}_{2}^{\overline{-}}$-generating system (xanthine [Xan]/xanthine oxidase [XO]). Values are the pooled means \pm SD (bars) of three experiments. Horizontal axis indicates time from the end of treatments. The addition of superoxide dismutase to the XAN + XO treatment partially prevented the effect of the $\mathrm{O}_{2}^{\bar{a}}$ generating system on yeast cells (data not shown). 
isolate LS-11 at all times tested (Fig. 4A and C). These enzymes together completely prevented the drop in wound colonization by LS-11 CFU observed in the untreated control and provided a much higher colonization of apple wounds than any other treatment. Positive effects also were recorded in the presence of CAT and SOD alone. Considerable increases in wound colonization also were recorded when LS-28 was applied with SOD plus CAT or CAT alone, at all times tested (Fig. 4B and D). Colonization of wounds by the two biocontrol yeasts was lower in older apples at all times tested, regardless of the presence of RDE, combined or alone (Fig. 4A to D). The presence of BSA did not substantially affect the colonization of wounds by isolate LS-11 and LS-28 in apples of both ages (Fig. 4A to D).

Antagonistic activity assays. Isolate LS-28 was confirmed as a more active antagonist than LS-11 in almost all activity assays (Figs. 5A and 6A and B). Only in older apples was LS-11 more antagonistic to $B$. cinerea than LS-28 (Fig. 5B). Factorial analysis showed that the effects of antagonistic yeasts (LS-11 and LS-28), amendments (BSA, $\mathrm{H}_{2} \mathrm{O}$, and $\mathrm{RDE}$ ), and their interaction were highly significant $(P<0.01)$ in each experimental block (Table 1$)$. The application of the two biocontrol yeasts in the presence of RDE had significant positive effects on their activity against $B$. cinerea and $P$. expansum, both on 1-month-old and 7-month-old apples. However, both the activities of the yeasts and the enhancement effect of RDE on their protective ability were lower in older ones (Figs. 5A and B and 6A and B). A 10-fold increase of antagonistic activity against $B$. cinerea was recorded when younger apples were treated with isolate LS-11 plus RDE with respect to the yeast alone (Fig. 5A). The addition of RDE to the same yeast yielded only a twofold increase of activity in older apples (Fig. 5B). In the case of $P$. expansum on younger apples, the protective effect of LS-11 combined with RDE was approximately five times higher than in the presence of the yeast alone (Fig. 6A). The enhancement by RDE was much less pronounced in older apples (Fig. 6B). Disease incidence due to B. cinerea was less than $1 \%$ when younger apples were treated with LS-28 plus RDE, whereas $8 \%$ incidence was observed with the yeast alone (Fig. 5A). An approximately threefold increase of protection was achieved when LS-28 was combined with RDE in 7-month-old apples (Fig. 5B). Protection of 1-month-old apples from $P$. expansum also was strikingly enhanced by RDE (4\% infected wounds versus $22 \%$ with LS-28 alone) (Fig. 6A). Again, as in the case of LS-11, the enhancement of LS-28 activity by RDE was weaker in older apples (Fig. 6B).

In apples of both ages challenged with $B$. cinerea and, to a lower degree in younger apples challenged with $P$. expansum, the addition of RDE alone, without yeasts, was sufficient to significantly protect fruits in comparison with the controls, although to a lower degree than in the presence of RDE plus biocontrol yeasts (Figs. 5A and $\mathrm{B}$ and 6A).

In all experiments, the combined addition of yeasts and BSA lowered the protective ability of the biocontrol agents against both B. cinerea and P. expansum (Figs. 5A and B and 6A and B). When apple wounds were treated with only BSA before inoculation with pathogens, no differences in the disease incidence was recorded compared with the controls, except for $B$. cinerea on younger apples, where the protein caused an increase of infected wounds (Fig. 5A).

Polar lipids of biocontrol agents. The fatty acids pattern of PL was similar, both quantitatively and qualitatively, in the two biocontrol yeasts, with one important difference (Table 2). Isolate LS-11 contained, in its PL, approximately $5 \%$ of the more unsaturated $\alpha$ -
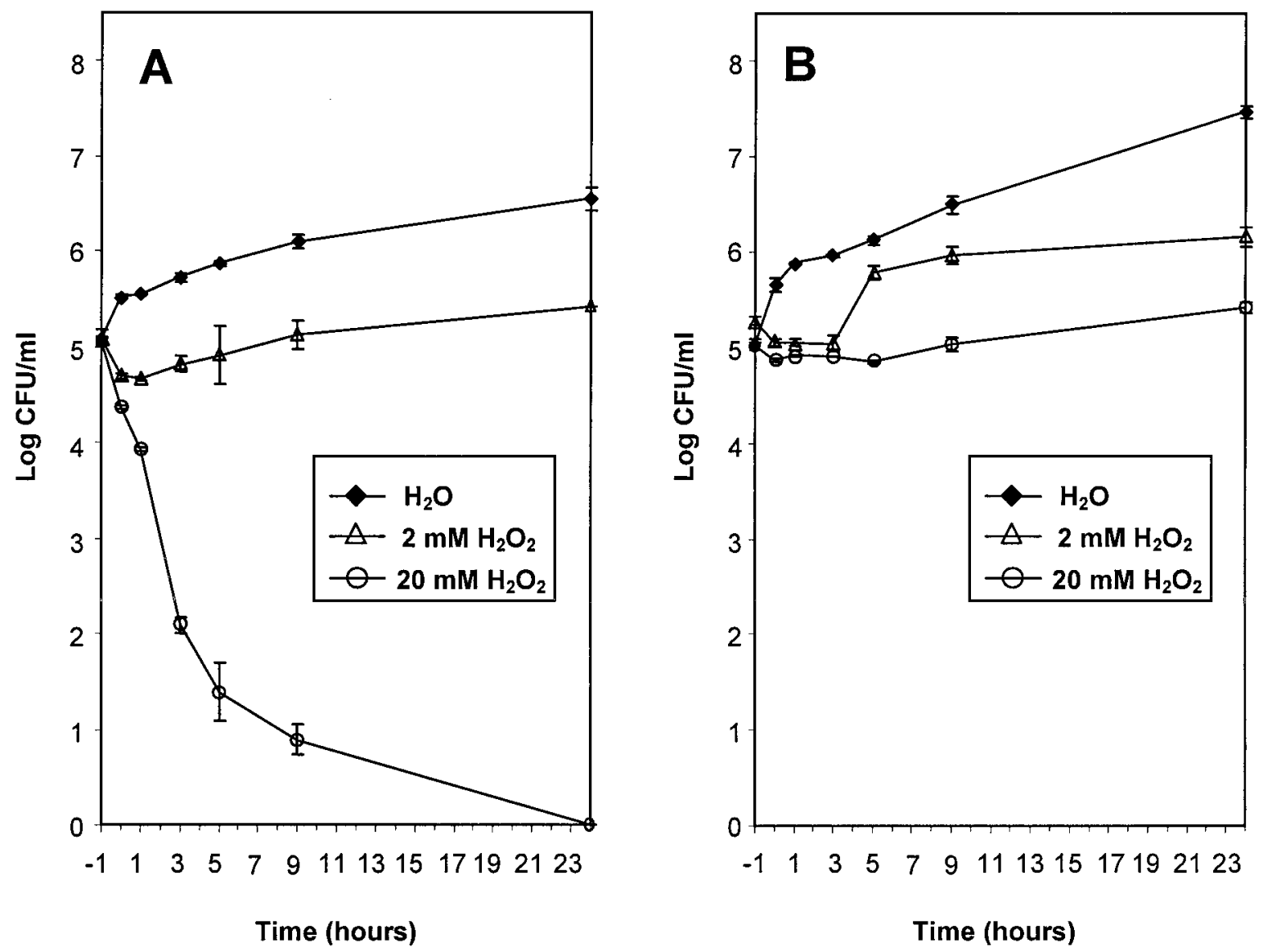

Fig. 3. In vitro survival of the biocontrol yeasts A, Rhodotorula glutinis LS-11 and $\mathbf{B}$, Cryptococcus laurentii LS-28, expressed as log CFU, following $1 \mathrm{~h}$ of treatment with 2 and $20 \mathrm{mM} \mathrm{H}_{2} \mathrm{O}_{2}$. Values are the pooled means $\pm \mathrm{SD}$ (bars) of three experiments. Horizontal axis indicates time from the end of treatments. The addition of catalase during the treatments prevented the effect of $\mathrm{H}_{2} \mathrm{O}_{2}$ on yeast cells (data not shown). 
linolenic acid (C18:3 n-3), which is absent in the same lipid fraction of isolate LS-28. Approximately the same levels of the other unsaturated fatty acids palmitoleic (C16:1 n-7), oleic (C18:1 $\mathrm{n}-9)$, and linoleic (C18:2 n-6) were detected in both yeast isolates.

\section{DISCUSSION}

Competition for space and nutrients is a major mechanism in the antagonism of biocontrol yeasts against fungal pathogens of stored agricultural produce $(5,6,9,10,26)$. B. cinerea and $P$. ex- pansum are important postharvest pathogens of pome fruits and penetrate host tissue mainly through wounds. Therefore, wound competence of biocontrol yeasts is pivotal to successfully compete for space and nutrients against these fungi (9). No reports exist in the literature focusing on the traits providing biocontrol yeasts with a sound wound competence (i.e., on the subset of mechanisms underlying a complex aspect of pathogen-antagonist interaction, such as competition for space and nutrients).

In this work, we examined the generation of ROS in wounded apple tissue soon after wounding and the wound competence of
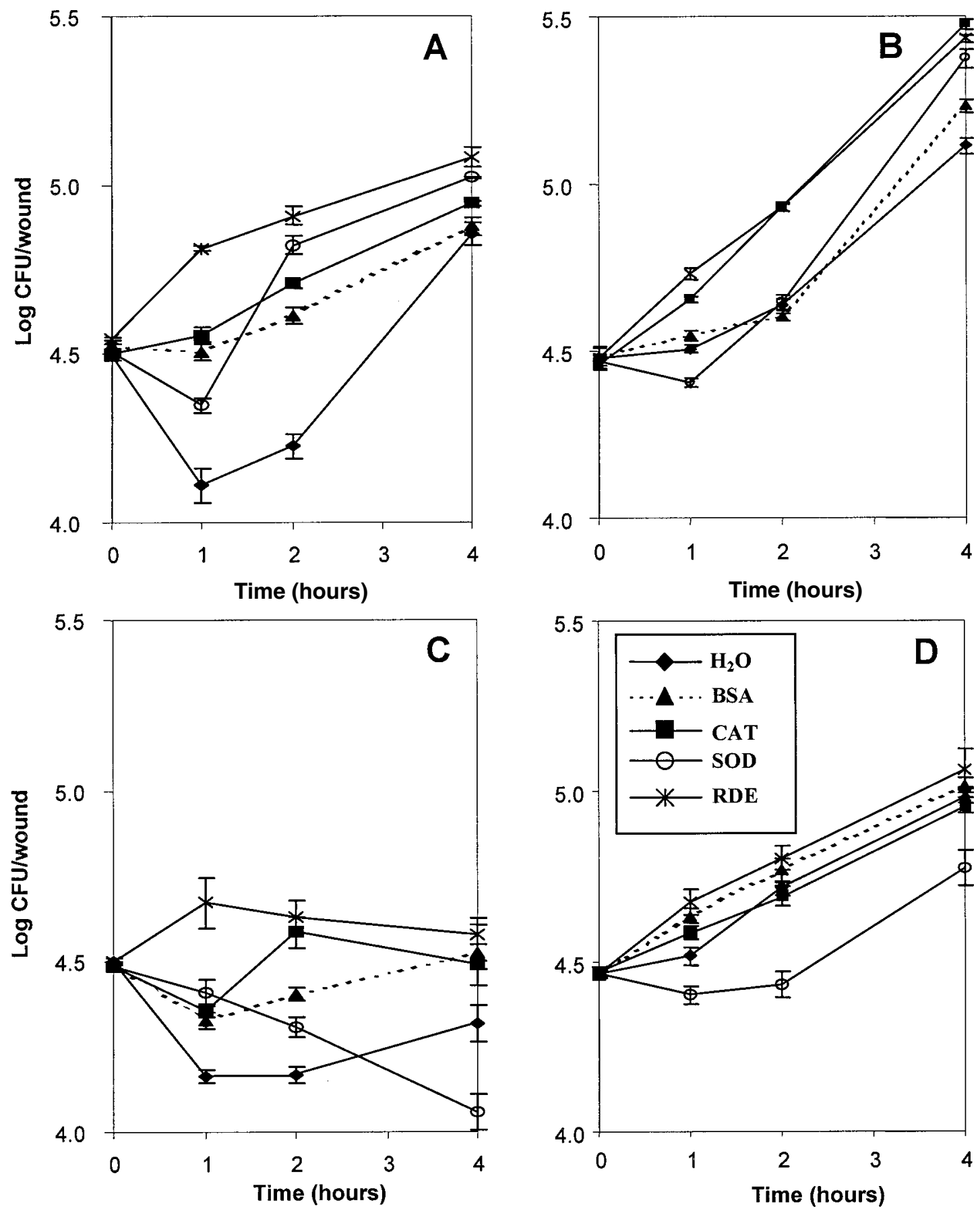

Fig. 4. Colonization of apple wounds of $\mathbf{A}$ and B, 1-month-old and $\mathbf{C}$ and D, 7-month-old apples by the biocontrol yeasts A and C, Rhodotorula glutinis LS-11 and $\mathbf{B}$ and D, Cryptococcus laurentii LS-28, expressed as $\log$ CFU, applied with or without reactive oxygen species-deactivating enzymes (RDE) (i.e., superoxide dismutase [SOD] and catalase [CAT]). SOD and CAT were added singularly (SOD or CAT treatments) or in combination (RDE treatments) to assess the effect of enzymes preventing accumulation of $\mathrm{O}_{2}^{\overline{-}}$ and $\mathrm{H}_{2} \mathrm{O}_{2}$ on colonization of wounds by the biocontrol agents. Bovine serum albumin was used as a control (BSA treatment) to evaluate the exogenous protein addition on the same phenomenon. Treatments " $\mathrm{H}_{2} \mathrm{O}$ " (controls) are the application of LS-11 or LS28 to apple wounds in the absence of any amendment. Values are the pooled means \pm SD (error bars) of two experiments. 
the two biocontrol yeasts LS-28 and LS-11, characterized by different levels of efficacy (LS-28 more efficient than LS-11) $(4,18)$. This was done by comparing their abilities to cope with ROSgenerated oxidative stress in vitro, to colonize fresh apple wounds, and to antagonize $B$. cinerea and $P$. expansum in the presence or in the absence of RDE. Our results clearly show that ROS generation occurs in apple wounds immediately after wounding and that it continues for up to $4 \mathrm{~h}$, at least. Further, generation of $\mathrm{H}_{2} \mathrm{O}_{2}$ and $\mathrm{O}_{2}^{\overline{-}}$ in old apples is more rapid and more pronounced than in younger ones. This finding is in agreement with the general phenomenon of higher levels of oxidant species in more senescent tissues $(13,24)$. Studies on pear fruit have shown that, during ripening, the concentration of free sulfhydryl groups decreases, while concentrations of $\mathrm{H}_{2} \mathrm{O}_{2}$ and lipid peroxides increase (13).

The more active antagonist LS-28 shows a higher wound competence than the less active antagonist LS-11. Isolate LS-28 is both more resistant to ROS-generated oxidative stress and a faster and more efficient colonizer of fresh apple wounds. Indeed, LS-28 does not appear to suffer from the stress affecting LS-11 cells soon after their application in fresh wounds. Therefore, the number of LS-28 cells facing fungal conidia inoculated in wounds
(1 to $1.5 \mathrm{~h}$ after yeast application) is much higher than that of LS11 cells, and this could explain its higher antagonistic activity with respect to LS-11 recorded in almost all antagonist activity assays. The strikingly positive effect of SOD plus CAT on both wound colonization and antagonistic activity by the two biocontrol agents is a clear indication of the oxidative nature of the mentioned stress. These enzymes completely prevent the stress affecting LS-11 at the first times following its application in wounds, and strongly enhance wound colonization by both LS-11 and LS-28 at all times tested. In the case of antagonistic activity, the interaction between biocontrol yeasts (LS-11 and LS-28) and RDE (as well as with other amendments, BSA, and $\mathrm{H}_{2} \mathrm{O}$ ) is highly significant. In some cases (LS-11 plus RDE against $P$. expansum on 1-month-old apples, LS-11 and LS-28 plus RDE against $P$. expansum and against $B$. cinerea on 7-month-old apples) the decrease of disease incidence recorded in the presence of the biocontrol yeasts plus RDE is clearly higher than that achieved by the single biocontrol yeasts and by RDE alone (without yeasts). This suggests that, in such cases, a possibly synergistic interaction may occur between biocontrol agents and antioxidant enzymes.

The lower positive effects achieved with SOD or CAT alone on wound colonization by LS-11 probably is due to the scavenging of
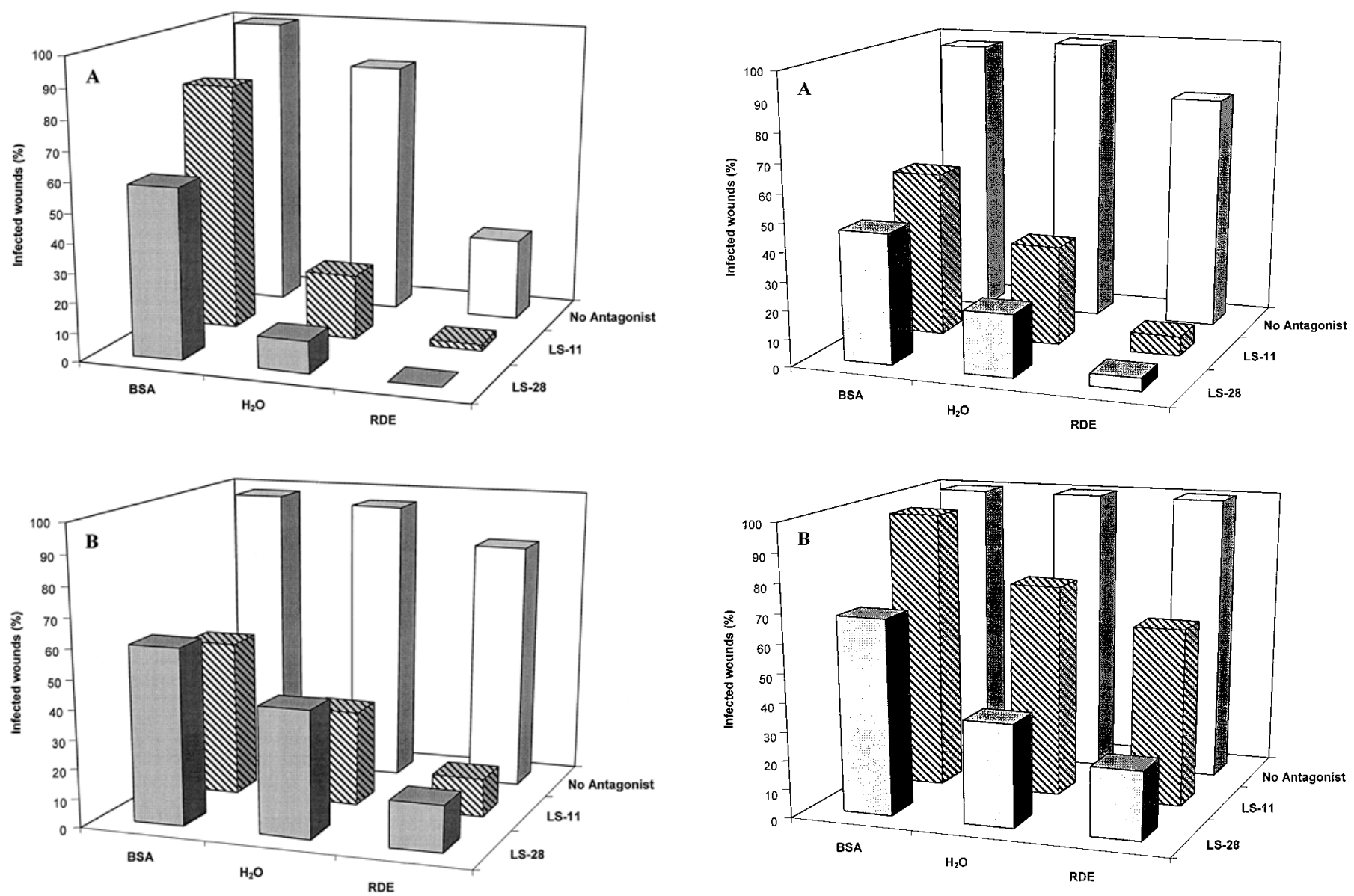

Fig. 5. Antagonistic activity of the biocontrol yeasts Rhodotorula glutinis LS-11 and Cryptococcus laurentii LS-28 against Botrytis cinerea on A, young (1 month after harvest) and $\mathbf{B}$, old (7 months after harvest) wounded apples, in the absence or presence of exogenously added reactive oxygen species-deactivating enzymes (RDE) (i.e., superoxide dismutase [SOD] and catalase [CAT]). SOD and CAT were used in combination (RDE treatments) to assess the effect of enzymes preventing accumulation of $\mathrm{O}_{2}^{\bar{z}}$ and $\mathrm{H}_{2} \mathrm{O}_{2}$ on antagonistic activity. Bovine serum albumin was used as a control (BSA treatment) to evaluate the exogenous protein addition on the same phenomenon. Means, based on combined data from three experiments, were separated by the least significant difference (LSD) test $(P<0.01)$. LSD = 1.62 and $2.30 \%$ in $\mathbf{A}$ and $\mathbf{B}$, respectively.

Fig. 6. Antagonistic activity of the biocontrol yeasts Rhodotorula glutinis LS-11 and Cryptococcus laurentii LS-28 against Penicillium expansum on A, young (1 month after harvest) and $\mathbf{B}$, old (7 months after harvest) wounded apples, in the absence or presence of exogenously added reactive oxygen species-deactivating enzymes (RDE) (i.e., superoxide dismutase [SOD] and catalase [CAT]). SOD and CAT were used in combination (RDE treatments) to assess the effect of enzymes preventing accumulation of $\mathrm{O}_{2}^{\mathbf{a}}$ and $\mathrm{H}_{2} \mathrm{O}_{2}$ on antagonistic activity. Bovine serum albumin was used as a control (BSA treatment) to evaluate the exogenous protein addition on the same phenomenon. Means, based on combined data from three experiments, were separated by the least significant difference (LSD) test $(P<0.01)$. $\mathrm{LSD}=3.07$ and $3.78 \%$ in $\mathbf{A}$ and $\mathbf{B}$, respectively. 
only $\mathrm{O}_{2}^{\overline{-}}$ or $\mathrm{H}_{2} \mathrm{O}_{2}$, respectively, in such treatments. The enhancement of antagonistic activity of both yeasts in the presence of SOD plus CAT is evident and more pronounced in younger apples. The latter aspect could be explained by the higher aggressiveness of necrotrophic pathogens, in particular Botrytis spp., on older plant tissues or by the higher levels of ROS detected in old apples. The enhancement of the yeasts' protective activity by RDE appears to be due to an increase of wound colonization by these biocontrol agents. However, a direct protective effect of the two enzymes together also is evident, especially in the case of $B$. cinerea in young and old apples and, although to a lower extent, in the case of $P$. expansum in young apples, when such enzymes were applied alone, without yeasts. B. cinerea is a necrotroph pathogen that induces and/or produces ROS generation when attacking plant tissues, possibly to kill host cells $(11,20,22)$. The light protective effect of RDE alone against $P$. expansum recorded in young apples suggests that the alteration of the oxidoreductive equilibrium of the host tissue could be a general phenomenon favoring infections by necrotroph pathogens.

In our previous researches, isolate LS-28 always displayed a higher antagonistic activity than isolate LS-11 against $B$. cinerea and $P$. expansum $(4,18)$. In these researches $(4,18)$, however, the age of apples had not been taken into consideration. The slightly higher activity of LS-11 applied alone against $B$. cinerea, which was recorded only on old apples, and the lower wound colonization by LS-11 on these apples represent an apparent exception to the rule that higher colonization of wounds by biocontrol yeasts corresponds to higher antagonist activity. This suggests that, besides resistance to wound-generated oxidative stress, other mechanisms, such as secretion of glucanase or other substances, could play an important role in the particular yeast $-B$. cinerea interaction on older apples. Such mechanisms might be more active in isolate LS-11 in the older apples- $B$. cinerea combination, thus compensating for reduced wound colonization by this yeast.

The presence of BSA did not negatively affect or even increase the colonization of wounds by isolate LS-11 and LS-28 in apples of both ages; however, in the presence of fungal pathogens, this protein favored infections. This is in agreement with the known detrimental effects of exogenous nutrient addition on antagonistic activity of these as well other yeasts $(5,6,9,10$, 26). More importantly, it confirms that the enhancement of LS-11 and LS-28 activity is not due to a "nutrient" effect of SOD or CAT as a protein, but to their nature of ROS-deactivating enzymes.
In living organisms, unsaturated fatty acids of membrane PL are major targets of oxidative stress $(7,13,24)$. A possible reason for the lower resistance of LS-11 to this stress (and its lower antagonist activity) could be the presence of the polyunsaturated $\alpha$ linolenic acid, more susceptible to oxidation than less unsaturated fatty acids, as those detected both in its PL and in those of LS-28. Other possible explanations could be a different pattern of regulation or slower induction of LS-11 antioxidant enzymes, namely SOD and CAT; differences in the activity of these enzymes; and the presence or absence of antioxidant compounds or different levels of their production by the two biocontrol yeasts. Experiments are in progress for clarifying these aspects. It must be emphasized, however, that the presence of more unsaturated fatty acids, such as $\alpha$-linolenic acid, can be an advantageous trait, because they provide membranes with a higher fluidity and functionality at lower temperatures. This can be useful when antagonists are to be applied during cold storage and probably explains the higher adaptability and activity of isolate LS-11 at low temperature (18).

In conclusion, our findings suggest that resistance to oxidative stress could represent a pivotal mechanism of action involved in wound competence of biocontrol yeasts. This could allow these microorganisms to successfully outcompete wound pathogens such as $B$. cinerea and $P$. expansum, thus preventing rots caused by these fungi. Further, especially in the case of $B$. cinerea, a role of antagonist yeasts as exogenous suppliers of antioxidant activity to the host tissue also could account partially for their protective ability, by providing the host tissue itself with additional defense tools counteracting ROS production and/or induction by this pathogen.

TABLE 2. Percent composition of prevalent fatty acids detected in the polar lipid fractions of the biocontrol yeasts Rhodotorula glutinis LS-11 and Cryptococcus laurentii LS-28

\begin{tabular}{lcc}
\hline & \multicolumn{2}{c}{ Antagonist $^{\mathrm{a}}$} \\
\cline { 2 - 3 } Fatty acid & LS-11 & LS-28 \\
\hline Palmitic acid (C16:0) & $12.3 \pm 2.3$ & $11.9 \pm 1.6$ \\
Palmitoleic acid (C16:1 n-7) & $2.6 \pm 0.5$ & $2.2 \pm 0.9$ \\
Stearic acid (C18:0) & $0.5 \pm 0.3$ & $0.7 \pm 0.3$ \\
Oleic acid (C18:1 n-9) & $57.2 \pm 10.4$ & $62.1 \pm 5.5$ \\
Linoleic acid (C18:2 n-6) & $22.2 \pm 4.0$ & $23.2 \pm 2.4$ \\
Linolenic acid (C18:3 n-3) & $5.2 \pm 1.0$ & $\mathrm{ND}$ \\
\hline a Percent values are the pooled means of two experiments \pm SD. In each \\
experiment, analyses were repeated twice. ND = not detected.
\end{tabular}

TABLE 1. Analysis of variance for the influence of antagonistic yeasts (LS-11 and LS-28) and amendments on percentage of wounds infected by postharvest fungal pathogens (Botrytis cinerea or Penicillium expansum) on 1- and 7-month-old apples ${ }^{\mathrm{a}}$

\begin{tabular}{|c|c|c|c|c|c|c|c|}
\hline \multirow[b]{2}{*}{ Source of variability } & \multirow[b]{2}{*}{ df } & \multicolumn{3}{|c|}{ B. cinerea } & \multicolumn{3}{|c|}{ P. expansum } \\
\hline & & $\mathrm{SS}^{\mathrm{b}}$ & $F$ & $P>F^{\mathrm{c}}$ & $\mathrm{SS}^{\mathrm{b}}$ & $F$ & $P>F^{c}$ \\
\hline \multicolumn{8}{|l|}{ 1-month-old apples } \\
\hline Experiment & 2 & 19.08 & 1.87 & 0.156 & 13.93 & 0.34 & 0.710 \\
\hline Amendment (B) & 2 & 204,087 & 20,011 & 0.000 & 52,405 & 1,290 & 0.000 \\
\hline $\mathrm{A} \times \mathrm{B}$ & 4 & 22,509 & 1,104 & 0.000 & 11,813 & 145 & 0.000 \\
\hline Error & 232 & 1,235 & $\ldots$ & $\ldots$ & 4,439 & $\ldots$ & $\ldots$ \\
\hline Experiment & 2 & 2.99 & 0.14 & 0.873 & 5.93 & 0.10 & 0.909 \\
\hline Antagonist (A) & 2 & 174,762 & 7,947 & 0.000 & 142,641 & 2,291 & 0.000 \\
\hline Amendment (B) & 2 & 43,704 & 1,987 & 0.000 & 25,457 & 409 & 0.000 \\
\hline $\mathrm{A} \times \mathrm{B}$ & 4 & 7,848 & 178 & 0.000 & 13,160 & 106 & 0.000 \\
\hline Error & 232 & 2,493 & $\ldots$ & $\ldots$ & 6,751 & $\ldots$ & $\ldots$ \\
\hline Total & 242 & 22,810 & $\ldots$ & $\ldots$ & 188,015 & $\ldots$ & $\ldots$ \\
\hline
\end{tabular}

a Amendments: $\mathrm{H}_{2} \mathrm{O}$ (control), reactive oxygen species-deactivating enzymes (i.e., superoxide dismutase plus catalase), or bovine serum albumin.

${ }^{\mathrm{b}} \mathrm{SS}=$ sum of squares.

c Significance at $P<0.01$. 


\section{ACKNOWLEDGMENTS}

This research was funded in part by MURST Project 9907398792 , "Biotechnological approaches for postharvest control of Botrytis cinerea", by Molise Region P.O.P. "Studio del Meccanismo d'Azione degli Antiossidanti", and by University of Molise Fondo per la Ricerca di Ateneo. We thank S. Wright, D. Pastore, M. Lorito, and S. Vanadia for valuable comments regarding the manuscript.

\section{LITERATURE CITED}

1. Able, J. A., Guest, D. I., and Sutherland, M. W. 1998. Use of a new Tetrazolium-based assay to study the production of superoxide radicals by tobacco cell cultures challenged with avirulent zoospores of Phytophthora parasitica var. nicotianae. Plant Physiol. 117:491-499.

2. Black, M. J., and Brandt, R. B. 1974. Spectrofluorometric analysis of hydrogen peroxide. Anal. Biochem. 58:246-254.

3. Bolwell, G. P. 1999. Role of active oxygen species and NO in plant defense responses. Curr. Opin. Plant Biol. 2:287-294.

4. Castoria, R., Caputo L., and De Cicco, V. 2001. Resistance to oxidative stress and antagonism of biocontrol yeasts against postharvest pathogens. IOBC/WPRS (Int. Organ. Biol. Integrated Control Noxious Animals Plants/West Paleartic Reg. Sect.) Bull. 24:303-307.

5. Castoria, R., De Curtis, F., Lima, G., Caputo, L., Pacifico, S., and De Cicco, V. 2001. Aureobasidium pullulans (LS-30), an antagonist of postharvest pathogens of fruits: Study on its modes of action. Postharvest Biol. Technol. 22:7-17.

6. Castoria, R., De Curtis, F., Lima, G., and De Cicco, V. 1997. ß-1,3Glucanase activity of two saprophytic yeasts and possible mode of action as biocontrol agents against postharvest diseases. Postharvest Biol. Technol. 12:293-300.

7. Chaput, M., and Sels, A. 1987. Sensitivity of yeast cells to reactive oxygen species generated in the extracellular space. Biochimie 69:53-62.

8. Doke, N., Miura, Y., Chai, H. B., and Kawakita, K. 1991. Involvement of active oxygen species in induction of plant defense response against infection and injury. Pages 84-96 in: Active Oxygen/Oxidative Stress and Plant Metabolism. E. Pelt and K. Steffen, eds. Am. Soc. Plant Physiol., Rockville, MD.

9. Droby, S., and Chalutz, E. 1994. Mode of action of biocontrol agents of postharvest diseases. Pages 63-75 in: Biological Control of Postharvest Diseases-Theory and Practice. C. L. Wilson and M. E. Wisniewski, eds. CRC Press, Boca Raton, FL.

10. Droby, S., Chalutz, E., Wilson, C. L., and Wisniewski, M. 1989. Characterization of the biocontrol activity of Debaryomyces hansenii in the control Penicillium digitatum on grapefruit. Can. J. Microbiol. 35:794800.

11. Elad, Y. 1997. Responses of plants to infection by Botrytis cinerea and novel means involved in reducing their susceptibility to infection. Biol. Rev. Cambridge Philos. Soc. 72:381-422.

12. Fabbri, A. A., Fanelli, C., Reverberi, M., Ricelli, A., Camera, E., Urbanelli, S., Rossigni. A., Picardo, M., and Altamura, M. M. 2000.
Early physiological and cytological events induced by wounding in potato tuber. J. Exp. Bot. 51:1267-1275.

13. Halliwell, B., and Gutteridge, J. M. C. 1991. Free Radicals in Biology and Medicine. 2nd ed. Oxford University Press, New York

14. Jiang, Z. Y., Woollard, A. C. S., and Wolff, S. P. 1990. Hydrogen peroxide production during experimental protein glication FEBS Lett. 268:69-71.

15. Jijakli, M. H., and Lepoivre, P. 1998. Characterization of an exo- $\beta$-glucanase produced by Pichia anomala strain K, antagonist of Botrytis cinerea on apples. Phytopathology 88:335-343.

16. Lee, S., Suh, S., Kim, S., Crain, R. C., Kwak, J. M., Man, H. G. M., and Lee, Y. 1997. Systemic elevation of phosphatidic acid and lysophospholipid levels in wounded plants. Plant J. 12:547-556.

17. Lilly, V. G., and Barnett, H. L. 1951. Physiology of the Fungi. McGrawHill, New York.

18. Lima, G., De Curtis, F., Castoria, R., and De Cicco, V. 1998. Activity of the yeasts Cryptococcus laurentii and Rhodotorula glutinis against postharvest rots on different fruits. Biocontrol Sci. Technol. 8:257-267.

19. Passi, S., Morrone, A., Picardo, M., De Luca, C., and Ippolito, F. 1991. Blood levels of vitamin E, polyunsaturated fatty acids of phospholipids, lipoperoxides and glutathione peroxidase in patients affected with seborrheic dermatitis, J. Dermatol. Sci. 2:171-178.

20. Prins, T., Tudzinsky, P., Von Tiedemann, A., Tudzinsky, B., Ten Have, A., Hansen, M. E., Tenberge, K., and Van Kan, J. A. L. 2000. Infection strategies of Botrytis cinerea and related necrotrophic pathogens. Pages 33-36 in: Fungal Pathology. J. W. Kronstad, ed. Kluwer Academic Publishers, Dordrecht, The Netherlands.

21. Sutherland, M. W., and Learmonth, B. A. 1997. The tetrazolium dyes MTS and XTT provide new quantitative assays for superoxide and superoxide dismutase. Free Radic. Res. 27:283-289.

22. Tiedemann, A. V. 1997. Evidence for a primary role of active oxygen species in induction of host cell death during infection of bean leaves with Botrytis cinerea. Physiol. Mol. Plant Pathol. 50:151-166.

23. Theologies, A., and Laties, G. G. 1981. Wound-induced lipid breakdown in potato tuber. Plant Physiol. 68:53-58.

24. Thompson, J. E., Legge, R. L., and Barber, R. F. 1987. The role of free radicals in senescence and wounding. New Phytol. 105:317-344.

25. Wilson, C. L., El Ghaouth, A., Chalutz, E., Droby, S., Stevens, C., Lu, J. Y., Khan, V., and Arul, J. 1994. Potential of induced resistance to control postharvest diseases of fruits and vegetables. Plant Dis. 78:837-844.

26. Wilson, C. L., and Wisnieswski, M. E. 1989. Biological control of postharvest diseases of fruits and vegetables: An emerging technology. Annu. Rev. Phytopathol. 27:425-441.

27. Wilson, C. L., and Wisniewski, M. E. 1994. Biological Control of Postharvest Diseases-Theory and Practice. CRC Press, Boca Raton, FL.

28. Wisniewski, M., Biles, C., Droby, S., McLaughlin, R., Wilson, C., and Chalutz, E. 1991. Mode of action of the postharvest biocontrol yeast Pichia guillermondii. I. Characterization of attachment to Botrytis cinerea. Physiol. Mol. Plant Pathol. 39:245-258.

29. Wolff, S. 1994. Ferrous ion oxidation in presence of ferric ion indicator xylenol orange for measurement of hydroperoxides. Pages 182-189 in: Methods in Enzymology 233, part C. Academic Press, San Diego, CA. 